\title{
MEASURING WELFARE LOSSES FROM HYPOXIA: THE CASE OF NORTH CAROLINA BROWN SHRIMP
}

\author{
Ling Huang \\ Assistant Professor \\ Department of Economics \\ University of Connecticut \\ 341 Mansfield Road, Unit 1063 \\ Storrs, CT 06269-1063 \\ ling.huang@uconn.edu \\ ph: (860) 486-3272 \\ fax: (860) 486-4463 \\ Lauren A.B. Nichols \\ Nicholas School of the Environment \\ Duke University \\ Box 90328 \\ Durham, NC 27709 \\ labnichols@gmail.com \\ ph: (919) 613-8000 \\ fax: (919) 684-8741 \\ J. Kevin Craig \\ NOAA National Marine Fisheries Service \\ Southeast Fisheries Science Center, Beaufort Lab \\ 101 Pivers Island $\mathrm{Rd}$. \\ Beaufort, NC 28516 \\ kevin.craig@noaa.gov \\ ph: (252) 728-8710 \\ fax: (252) 728-8619
}

Martin D. Smith (corresponding author)

The Dan and Bunny Gabel Associate Professor of Environmental Economics

Nicholas School of the Environment and Department of Economics

Duke University

Box 90328

Durham, NC 27709

marsmith@duke.edu

ph: (919) 613-8028

fax: (919) 684-8741 


\section{ACKNOWLEDGMENTS}

We thank two anonymous reviewers, the editors, and participants at the 2010 International Institute of Fisheries Economics and Trade (IIFET) Conference in Montpellier France for helpful comments on earlier versions of this work. We thank the North Carolina Division of Marine Fisheries for access to shrimp fishery and monitoring data. We also thank R. Traynor of the U.S. Geological Survey and the MODMON program at the UNC-Chapel Hill Institute of Marine Science for access to environmental monitoring data for the Neuse River. Financial support for this project was provided by the National Oceanic and Atmospheric administration (NOAA) Center for Sponsored Coastal Ocean Research under award \# NA05NOS4781197 to J. Kevin Craig, Larry B. Crowder, and Martin D. Smith (Duke University). This is CHRRP publication number 164. The views expressed herein are those of the authors and do not necessarily reflect the view of NOAA or any of its sub-agencies.

Running title: Economic Effects of Hypoxia 


\title{
MEASURING WELFARE LOSSES FROM HYPOXIA: THE CASE OF NORTH CAROLINA BROWN SHRIMP
}

\begin{abstract}
While environmental stressors such as hypoxia (low dissolved oxygen) are perceived as a threat to the productivity of coastal ecosystems, policy makers have little information about the economic consequences for fisheries. Recent work on hypoxia develops a bioeconomic model to harness microdata and quantify the effects of hypoxia on North Carolina's brown shrimp fishery. This work finds that hypoxia is responsible for a $12.9 \%$ decrease in NC brown shrimp catches from 1999-2005 in the Neuse River Estuary and Pamlico Sound, assuming that vessels do not react to changes in abundance. The current article extends this work to explore the full economic consequences of hypoxia on the supply and demand for brown shrimp. Demand analysis reveals that the NC shrimp industry is too small to influence prices, which are driven entirely by imports and other domestic U.S. harvest. Thus, demand is flat and there are no measurable benefits to shrimp consumers from reduced hypoxia. On the supply side, we find that the shrimp fleet responds to variation in price, abundance, and weather. Hence, the supply curve has some elasticity. Producer benefits of reduced hypoxia are less than a quarter of the computed gains from assuming no behavioral adjustment.
\end{abstract}

Key words Hypoxia, dead zones, nutrient pollution, welfare analysis, bioeconomics, ecosystembased management.

JEL Classification Code Q22. 


\section{Introduction}

Land use changes associated with population growth and agricultural production have led to increased nutrient loading in many U.S. waterways. The resulting anthropogenic eutrophication can significantly alter the ecosystem structure and function of the estuarine and coastal environments downstream (Rabalais et al. 1996; NRC 2000; Diaz and Rosenberg 2008). One of the major environmental outcomes from excess nutrient loading, especially the influx of nitrates, is hypoxia (Hagy et al. 2004), which is often defined as dissolved oxygen levels below $2 \mathrm{mg} / \mathrm{L}$ in aquatic systems. Hypoxia is typically caused by the decay of excess primary productivity stimulated by high nutrient concentrations in combination with a reduction in the re-supply of oxygen from surface waters.

Hypoxia can have lethal and sub-lethal consequences for harvested marine populations (Craig et al. 2001; Breitburg et al. 2009). Fish and shellfish directly exposed to hypoxic waters experience decreased growth (Stierhoff, Targett, and Power 2009), reduced reproduction (Thomas et al. 2007), and increased mortality (Miller, Poucher, and Coiro 2002). For harvested species, all of these impacts reduce the biomass available for harvest and are expected to be costly to fisheries. Individuals also move to avoid hypoxia, which can lead to aggregations along the edges of hypoxic zones (Craig and Crowder 2005; Craig 2012). Aggregation effects might actually benefit fisheries in the short run by increasing catchability, but movement away from hypoxic zones still requires energy that could otherwise be used for growth and reproduction. As such, the net economic consequences of avoidance behavior are unclear.

Qualitatively, the ecological consequences of hypoxia are cause for concern, but quantifying the economic costs presents numerous challenges. First, fish stocks are not directly observable, a complication that plagues fisheries management in general. Therefore, the state of the stock and 
the amount of mortality imposed by environmental degradation and fishing has a high degree of uncertainty. Moreover, hypoxia can have multiple effects on aspects of productivity and harvest that may occur simultaneously or over a range of spatial and temporal scales in the ecosystem, so quantifying these effects outside of a laboratory requires many degrees of freedom. Hence, it is not surprising that studies using spatially and temporally aggregated data often have low statistical power and generally fail to detect statistically significant fishery impacts of hypoxia (Zimmerman, Nance, and Wiams 1996; Diaz and Solow 1999).

As an alternative to aggregate data, economists have used data on individual fisherman and fishing trips (microdata) to quantify the economic effects of hypoxia on fisheries (Lipton and Hicks 2003; Mistiaen, Strand, and Lipton 2003; Massey, Newbold, and Gentner 2006). Microdata allow for much larger degrees of freedom and, hence, statistical power, to detect the effects of hypoxia. Microdata also allow for the control of spatial and temporal differences in fishing effort on catch, which is often a confounding factor in analyses of environmental effects on fisheries. While the increasing availability of fishery microdata allows a high degree of flexibility in modeling environmental effects on fisheries, its full potential has not been realized. For example, previous work using microdata has ignored the possibility that the effects of hypoxia on harvest do not materialize instantaneously, but involve a lagged process, with catches reflecting cumulative past exposure to environmental conditions. It is unlikely that direct exposure to hypoxia, or, indeed, most environmental stressors, results in an instantaneous effect on catch. This failure to account for lagged effects is another potential explanation for the lack of significant hypoxia effects in prior studies.

In a recent paper, Huang, Smith, and Craig (2010), HSC hereafter, propose using a panel data approach to address the challenges of quantifying the net economic costs of hypoxia for 
fisheries. A panel model allows one to difference out unobservable parameters of the biological model, including natural mortality and migration parameters. The panel model also allows the researcher to account for the cumulative effects of past hypoxia while controlling for contemporaneous effects, such as increased catchability as a result of avoidance behavior or direct mortality. HSC estimate a model with microdata from the North Carolina brown shrimp fishery combined with water quality monitoring data from the Neuse River Estuary. Brown shrimp are an annual species, and much of the exposure to low dissolved oxygen occurs when the shrimp are below harvestable size in the estuarine nursery areas (Minello, Zimmerman, and Martinez 1989; Eby and Crowder 2002). Negative effects on growth may not be evident in catch data until weeks or even months later, while aggregation effects on catchability to the fishery should be nearly instantaneous. The authors use their model to quantify revenue losses under the assumption that the harvest sector does not alter its behavior in response to changing shrimp biomass and prices. HSC find a 10-15\% decrease in catches due to hypoxia, which translates into revenue losses in the range of $\$ 1.25$ million per year. However, the model assumes no behavioral adjustment of the harvest sector. In order to quantify the economic costs of hypoxia, it is necessary to empirically model fishing behavior and compute changes in producer and consumer surplus.

In this article, we extend HSC with a logit model of North Carolina shrimp fisherman participation behavior. Qualitatively, results of the extended model show that individual shrimp vessels respond to economic incentives as expected, exerting more effort when prices or stocks are higher. We then conduct demand analysis on the North Carolina shrimp fishery and find that the demand curve is effectively flat; demand is not statistically distinguishable from being perfectly elastic. This finding is not surprising in light of North Carolina's small share of total 
shrimp consumption in the U.S. and the likely degree of market integration. Thus, there are no quantifiable consumer surplus losses in the North Carolina shrimp market attributable to hypoxia. When the harvest sector is allowed to alter its behavior in response to shrimp biomass and prices, we find that producer surplus losses from hypoxia are roughly one quarter of the revenue losses computed in HSC, which assumes no behavioral adjustment of the fishery.

The article is organized as follows. First, we describe the North Carolina shrimp fishery, the biology of brown shrimp, and the likely effects of hypoxia. Second, we review the HSC model and our model for extending the results to the entire fishery. Third, we present our behavioral model for the shrimp fishery and describe our market demand model. Fourth, we describe the data used in our estimation. We then review the HSC results, present our new econometric results, and compute the welfare effects of hypoxia. Finally, we discuss limitations of this work and important directions for future research.

\section{Empirical Background}

The North Carolina commercial wild-caught shrimp fishery consists of three major species, pink (Farfantepenaeus duorarum), white (Litopenaeus setiferus), and brown shrimp (Farfantepenaeus aztecus), that together make up one of the most economically important fisheries in the state (Holthuis 1980). In 2009 5,407,691 pounds of shrimp (head on) at a value of $\$ 8,527,675$ were landed in North Carolina. The total value of landings for the shrimp fishery currently ranks second only to the blue crab fishery. Of the three main shrimp species, brown shrimp is the most abundant in North Carolina waters, accounting for approximately $66 \%$ of the state's total shrimp landings (NCDMF 2006). Because the dynamics of growth and recruitment differ across species and hypoxia is likely to affect each species differently, we focus our analysis on the brown shrimp fishery. 
Brown shrimp, which are found along the Atlantic coast of the U.S. from Massachusetts to Texas as well as along parts of Mexico, reach reproductive maturity at approximately 4-6 months of age at which point they are approximately 5 inches in length. They can live up to 18 months and reach 7 inches in length, but the majority of brown shrimp do not live past one year. Spawning occurs offshore in deeper waters during the winter. Approximately 500,000 to $1,000,000$ eggs can be produced by each adult female. This high fecundity likely accounts for the weak stock-recruitment relationship of brown shrimp and the corresponding policy implication that recruitment overfishing is not a concern (NCDMF 2006). After fertilization and multiple larval stages, which can last between 11 and 17 days, the postlarval shrimp are carried by the tide into the shallow waters of estuaries between February and April. There they move into nurseries in river beds, marshes, and tidal inlets to feed and will grow rapidly (e.g., 0.02 to 0.1 inches per day) under favorable conditions. The young shrimp are omnivorous and will feed on algae, organic debris, and a number of smaller invertebrates (Gleason and Wellington 1988). When they reach the juvenile stage they begin to move back out towards higher salinity, deeper waters of sounds, and eventually return to the open ocean during the late summer and fall, primarily migrating at night. Young shrimp are preyed upon by a number of estuarine predators including sheepshead minnows, grass shrimp, insect larvae, and blue crabs. As larger juveniles and adults they are consumed by a variety of coastal finfishes (NMFS 2008; Sheridan Trimm, and Baker 1984).

Environmental hypoxia has been shown to induce both behavioral and physiological changes in many aquatic species (Wu 2002). An important behavioral response for understanding fishery impacts is avoidance behavior. Laboratory and field studies in the Neuse River Estuary indicate that brown shrimp have an avoidance threshold of 1-2 mg/l dissolved oxygen (Wannamaker and 
Rice 2000; Eby and Crowder 2002). Furthermore, brown shrimp appear to avoid severely low oxygen levels, but aggregate at high densities in areas of "moderately low dissolved oxygen" (1.6 to $3.7 \mathrm{mg} / \mathrm{l}$ ) near hypoxic edges (Craig and Crowder 2005; Craig 2012). These results suggest that behavioral changes and resulting shifts in spatial distribution could have energetic consequences and alter trophic interactions that ultimately have consequences for commercial harvest.

The most common physiological changes that have been observed in shrimp exposed to low levels of dissolved oxygen occur in their growth rate and metabolic processes. For example, juvenile white shrimp can survive moderately low levels of dissolved oxygen, but their growth rates decrease when exposed to dissolved oxygen levels below $4 \mathrm{mg} / 1$ (Rosas et al. 1998). Moreover, shrimp invest more time in assimilation of food at these lower levels of dissolved oxygen (Rosas et al. 1998). Another study identified a negative effect of severe hypoxia (1 mg/l dissolved oxygen) on the immune response of Penaeus stylirostris shrimp, further noting that the mortality of the hypoxia-stressed shrimp significantly increased when experimentally injected with a virulent (Moullac et al. 1998).

Although the ecological consequences of hypoxia are complex in and of themselves, disentangling the economic costs of hypoxia requires accounting for features that are exogenous to the ecological system. These include economic drivers of the shrimp fishery, some of which are sources of significant economic stress. In particular, rising imports of farmed shrimp have likely put downward pressure on shrimp prices even in a period when demand is growing (Keithly and Poudel 2008). At the same time, fuel prices have risen dramatically in the past decade. Fuel prices are likely to influence shrimp supplies because shrimp trawling is relatively fuel intensive. 


\section{Modeling the economic costs of hypoxia}

Our conceptual model for the welfare effects of hypoxia is simple. Hypoxia could shift (and/or rotate) the supply of shrimp resulting in consumer and producer surplus losses. What is complicated is that aggregate market-level data could obscure the effects of interest on the supply side. In this article, we recover the supply curve using individual-level data on a daily basis by econometrically modeling individual output and behavior. We then aggregate to the market level to conduct welfare analysis. We explore the possibility of lost consumer surplus by estimating demand at the market level, but we find no evidence of any inelasticity. That is, the demand for North Carolina shrimp appears to be perfectly elastic, and welfare losses can be measured entirely as producer surplus changes.

Hypoxia is a dynamic phenomenon in many estuarine nursery habitats, with oxygen conditions changing on time scales of hours to days (Reynolds-Fleming and Luettich 2004). To estimate the welfare consequences, we model daily fishery supply conditional on the presence of hypoxia. To this end, HSC model a harvest function that quantifies the contemporaneous and cumulative effects of hypoxia. Because the shrimp stock is not directly observable, the hypoxia effects are embedded into a detailed life history model that accounts for annual recruitment pulses, growth and aging, natural mortality, migration, and fishing mortality. Herein, we combine this harvest function with a model of the probability of fishing to arrive at the supply function.

Specifically, HSC estimate harvest functions for the Neuse River Estuary and Pamlico Sound, which together comprise over half of the North Carolina shrimp fishery. The approach is similar to that used in Smith, Zhang, and Coleman (2006) to quantify the impacts of marine reserves on catches in the Gulf of Mexico's reef-fish fisheries and in Zhang and Smith (2011) to 
estimate reef-fish stock dynamics from fishery-dependent data. Let $y$ denote year, $t$ denote day, $\mathrm{g}$ is a gear index, $m$ is a month index, and $i$ is a daily time index for accumulating past effects. We use $C$ to denote catch, which in some specifications is vessel-specific and in others is industry total catch. We use $H$ to denote past industry total catch for a period to distinguish it from contemporaneous catch. The logarithm of catch $(C)$ can be expressed as a function of catchability $(q)$, fishing effort $(K)$, average vessel size $(L e n)$, past fishing mortality $\left(m_{f}\right)$ in the current season $m_{f} \sum_{i=0}^{t-1} \frac{H_{y i}}{w_{i}}$, annual recruitment in numbers $(z)$, biological growth and mortality parameters $\left(w\right.$ for weight of an individual, $m_{0}$ for natural mortality rate, and $m_{l}$ for emigration rate), cumulative past environmental conditions ( $O I$ for whether the day is below the hypoxia threshold, $T I$ and $S I$ reflecting whether the day is outside the tolerable temperature or salinity ranges, respectively), and contemporaneous environmental conditions ( $O$ for oxygen, $T$ for temperature, and $S$ for salinity):

$$
\begin{aligned}
& \ln C_{y t}=\ln q_{y m, g}+\alpha \ln K_{y t}+\beta \ln \operatorname{Len}_{y t}+\gamma \ln z_{y 0}+\left(\ln w_{t}-m_{0 t}-m_{1 t}\right) \\
& m_{f} \sum_{i=0}^{t-1} \frac{H_{y i}}{w_{i}}+a_{1} \sum_{i=\tau-t+1}^{t} O I_{y i}+a_{2} \sum_{i=\tau-t+1}^{t} T I_{y i}+a_{3} \sum_{i=\tau-t+1}^{t} S I_{y i}+b_{1} \ln O_{y t} \\
& +b_{2} \ln T_{y t}+b_{3} \ln S_{y t}+\varepsilon_{y t} .
\end{aligned}
$$

This specification is consistent with a Cobb-Douglas production function with five key assumptions: 1) the coefficient on the fish stock is restricted to one (as in HSC and Smith, Zhang, and Coleman 2006), 2) effort and vessel length are separate inputs in the production function, 3) catchability is gear-, month-, and year-specific, 4) the fish stock is decomposed into the product of number of shrimp and weight of an individual shrimp, and 5) the environmental effects on the shrimp population are multiplicative. Assumption 1 is necessary for identification. Assumption 2 allows for more flexibility in the production function by admitting possible 
curvature that is typically assumed away in the Schaefer specification and by estimating separate effects of fishing trips and vessel size. Assumption 3 captures the possibilities that different gear types (shrimp trawl versus skimmer trawl, for instance) have different catching powers, and independent from seasonal changes in stocks, shrimp may aggregate more or less seasonally. Assumption 4 is a standard assumption for size-structured bioeconomic models. Note that $w$ represents the computed weight of an individual at age $t$ based on Minello, Zimmerman, and Martinez (1989); McCoy (1968); and Fontaine and Neal (1971). This term lumps together von Bertalannfy growth and allometric conversion (from weight to numbers) as in Clark (1990) and Smith, Zhang, and Coleman (2008). Because of assumption 4, the logarithmic specification is linear, and the environmental effects can be characterized by a series of linear terms in the regression model. Appendix A provides a detailed derivation of equation 1.

HSC estimate three different versions of the model in equation 1: one that aggregates data to the daily level and allows for first differencing to eliminate natural mortality and migration, one that uses individual-level data and requires assumptions about natural mortality and migration (based on the biological literature), and one that again uses aggregate data but allows a flexible functional form for the lagged effect of hypoxia using a polynomial distributed lag. All three models yield similar conclusions about the effects of hypoxia on catches and the associated fishing revenues. However, the first model makes the fewest assumptions and allows us to use first differencing to eliminate growth, mortality, and migration parameters. This gives us the greatest confidence in the first model's estimate of the parameter of interest, namely the effect of hypoxia on catches, and the other models serve as robustness checks.

Although the differenced model in HSC likely provides the highest precision for the hypoxia effect, it does not allow us to recover a complete model of the stock. To trace out the supply 
curve, we require a stock model and the ability to model individual-level catch data. To this end, we estimate the production function assuming that the coefficient we recovered on the hypoxia effect $\left(a_{1}\right)$ is the truth. Specifically, we estimate the following model:

$$
C_{i y t}=q_{y m} \operatorname{Len}_{i}^{\beta} z_{y 0}^{\gamma} e^{-m_{0}(t)} e^{a_{1} \sum_{n=y \tau-y t+1}^{y t} O I_{n}} w_{t} e^{a_{2} \sum_{k=1}^{t-1} \frac{H(k)}{w_{k}}} e^{\varepsilon_{y t}}
$$

By taking logs of equation 2 and rearranging, the dependent variable becomes:

$$
\log \left(C_{i y t}\right)-m_{0}(t)-\log \left(w_{t}\right)-a_{1} \sum_{n=y \tau-y t+1}^{y t} O I_{n}
$$

This allows us to estimate monthly catchabilities (ln $q_{y m}$ ), the effect of individual vessel length $(\beta)$, and the effects of cumulative fishing mortality on catches $\left(a_{2}\right)$ in a model that embeds the hypoxia effect. To model the probability of fishing $\left(p_{i y t}\right)$, we use a logit specification:

$$
p_{i y t}=\frac{e^{v_{i t}}}{1+e^{v_{i t}}}
$$

where the conditional indirect utility function $(v)$ includes the product of a set of drivers of fishing participation (price, stock, weather, diesel price, vessel length, and annual fixed effects) and an associated coefficient vector. Note that price is assumed exogenous on the supply side when modeling individual fishing participation decisions. The rationale is that even if NC shrimp price is responsive to quantity landed at the market level, it is reasonable to assume that individual shrimp harvesters are price takers. There are hundreds of individual vessels, and no one vessel can control a significant market share. As a practical matter, we find (below) on the demand side that the price does not even appear endogenous at the market level for NC shrimp, which reinforces our assumption of price-taking behavior of individual suppliers. Given estimation of the unknown parameters combined with life history parameters for brown shrimp taken from the literature, we can construct a stock index for use in the logit behavioral model. 
The term $z_{y 0} e^{-m_{0}(t)} e^{a_{1} \sum_{n=y \tau-y t+1}^{y t} O I_{n}} w_{t} e^{a_{2} \sum_{k=1}^{t-1} \frac{H(k)}{k}}$ in equation 2 is this time-varying stock proxy. A key point here is that parameters in a logit model are only identified up to scale. Thus, as long as the stock proxy captures relative changes in the stock, it will effectively predict behavior even if the initial abundance estimates (e.g., from biological surveys) are inaccurate in absolute terms. The use of the discrete choice model for behavior thus makes the stock proxy approach more appealing. Moreover, given that the production function is of the Schaefer type (catch is proportional to stock and effort), the inclusion of the stock proxy also serves as a model of expected catches (Smith, Sanchirico, and Wilen 2009). For a similar reason, we do not follow the Haynie and Layton (2009) approach. In their case, it is important to model expected profits in each location because, in part, there is no reliable stock proxy. In our case, we have a good stock proxy but extremely coarse information on the spatial choices and cannot meaningfully break down the choice set spatially.

The supply function $(Q)$ then simply aggregates over all vessels $(I)$ in the fleet on each day, multiplying the vessel's conditional catch by its probability of fishing that day:

$$
Q_{y t}^{S, \text { shrimp }}=\sum_{i=1}^{I} C_{i y t} * p_{i y t}
$$

which can be expressed in price-dependent form as:

$$
P_{y t}^{S, \text { shrimp }}=F\left(Q_{y t}^{S, \text { shrimp }}\right)
$$

In contrast to the supply side, we do not have individual data on the demand side and can only perform demand estimation at the market level. Thus, we need to consider the possibility that NC shrimp price is endogenous at the market level. Prices are only updated biweekly in the shrimp 
landings tickets, which limits the number of observations that we have at the market level, and other demand factors (e.g., income, prices of substitutes) are only available on a monthly basis. We model inverse demand — where $P$ represents price, $Q$ quantity, and $I$ income — as follows:

$$
P_{y m}^{D, \text { shrimp }}=\sum_{k=1}^{K} \theta_{k} P_{y m}^{\text {substitute }}+\theta_{K+1}+\theta_{K+2} Q_{y m}^{D, \text { shrimp }}+\theta_{K+3} I_{y m}
$$

We use the parameters in equations 5 - 7 to compute actual and counterfactual equilibrium price and quantity and the associated welfare effects from hypoxia reductions. The welfare change on a given day, $t$, from the state of "hypoxia" to "no hypoxia" is the sum of consumer and producer surplus changes:

$$
\int_{0}^{Q_{y t}^{S, \text { shrimp }} \mid \text { nohypoxia }} P_{y t}^{D, \text { shrimp }}-\left(P_{y t}^{S, \text { shrimp }} \mid \text { no hypoxia }\right) d Q-\int_{0}^{Q_{y t}^{S, \text { shrimp }} \text { hypoxia }} P_{y t}^{D, \text { shrimp }}-\left(P_{y t}^{S, \text { shrimp }} \mid \text { hypoxia }\right) d Q .
$$

Equation 8 is a general expression for the welfare effects where supply and demand are assumed linear.

\section{Data}

To quantify the welfare effects of hypoxia, we combine a number of data sets. We use harvest data from the North Carolina Division of Marine Fisheries trip ticket program. Each dealer reports commercial landings information for each individual fishing trip, including the gear type, trip starting and landing date, and price and quantity of landed fish and shrimp. From 1978 to 1993, North Carolina commercial landings information was collected on a voluntary basis. In 1994, the N.C. General Assembly mandated trip-level reporting of commercially harvested species. The data used in this article contain complete shrimp landings in the Neuse River and Pamlico Sound from 1999-2005. This is the period over which water quality has been continuously monitored in the Neuse River Estuary (Buzzelli et al. 2002). Price data are also 
obtained from the trip ticket program. The weighted average daily price of shrimp is calculated by dividing the total shrimp value (\$) on day $t$ by the total shrimp catch (lbs.) on the same day. Additional details on the shrimp microdata appear in HSC.

An important part of our production model and the behavioral model is the stock of shrimp. The production model is able to estimate the shrimp stock conditional on knowing the initial abundance and life history parameters. For initial abundance, we use annual monitoring surveys for shrimp and finfish conducted by North Carolina Division of Marine Fisheries. The shrimp survey (program 510) samples multiple stations throughout the Albemarle-Pamlico Sound estuarine system and its tributaries during the last week of May or first week of June. We calculate the average catch per unit effort (CPUE) of brown shrimp from each of these surveys, then average across the two surveys in each year to construct an annual index of initial brown shrimp abundance for each year from 1999 to 2005.

We use water quality monitoring data collected by the United States Geological Survey (USGS) from the Neuse River Estuary. Previous studies have documented that the Neuse River Estuary experiences severe and recurring hypoxia during the summer months that leads to fish kills and other ecological effects (Paerl et al. 1998; Lenihan et al. 2001; Eby et al. 2005). The data consist of surface and bottom measurements of dissolved oxygen, temperature, salinity, and other water quality variables at a 15-minute sampling interval from 1999 to 2005 from three moorings in the Neuse River. These data have been the basis for several water quality modeling efforts and other studies in the system (Borsuk et al. 2001; Stow et al. 2003). We take the average of the 15-minute values each day over these three moorings as a daily measure of environmental conditions. Because shrimp are demersal and strongly associated with the bottom, we use bottom values for dissolved oxygen, temperature, and salinity. We quantify the severity 
of hypoxia by calculating the number of days during which average bottom dissolved oxygen concentrations are below some threshold (e.g., $<2$ mg/l) in each year from 1999 to 2005; HSC also do robustness checks using ranges $<1.5 \mathrm{mg} / \mathrm{l}$ and $<2.5 \mathrm{mg} / \mathrm{l}$. The average number of hypoxic days over these seven years is 61 days per year for the range $<2 \mathrm{mg} / \mathrm{l}$. For temperature and salinity conditions, the intolerable temperature thresholds are defined as $<4.4{ }^{\circ} \mathrm{C}$ and $>32.2$ ${ }^{\circ} \mathrm{C}$, and the intolerable salinity threshold is $<5 \mathrm{ppt}$.

Beyond microdata and environmental data, we require weather information and fuel prices in order to estimate the behavioral model and trace out the daily shrimp supply curve. When modeling daily participation decisions in fisheries, weather is an important determinant of behavior (Smith and Wilen 2005). Conditioning on weather allows the analyst to resolve the economic influences on behavior more readily, and these influences are not perfectly orthogonal to weather indicators. Weather data, including wind speed and wave height, are compiled from the National Data Buoy Center. Since no buoy data directly represent the weather of the large Albemarle- Pamlico Estuary areas, we average weather data over three stations: Station DSLN7 (off of Cape Hatteras), Station CLKN7 (at Cape Lookout), and Station 44014 (off of the Northern Outer Banks). Fishing vessels use \#2 marine diesel, but a detailed time series of its price for the mid-Atlantic region is unavailable. As a substitute, we use weekly retail diesel prices obtained from the Energy Information Administration (EIA). Because logit model coefficients are only estimated up to scale, this proxy should perform well, as it will be highly correlated with marine diesel prices even if there are differences in the price levels.

To estimate our demand model, we require several additional covariates to represent prices of substitutes and income. Data on the price of imported shrimp for each month between January 1999 and December 2005 were obtained from the U.S. International Trade Commission 
(USITC). A query to the USITC dataweb system provided the current (landed-duty-paid value)/(first unit of quantity) for "shrimps and prawns, frozen" (SITC-03611) from all countries in dollars per kilogram by month. This value was then converted to dollars per pound and adjusted to real 2007 dollars using the 2007 consumer price index (CPI) for all commodities. U.S. per capita personal income data were obtained from the Bureau of Economic Analysis (BEA) website. These data were provided in chained 2000 dollars (seasonally adjusted at annual rates) and were then adjusted to real 2007 dollars again using the 2007 CPI for all commodities. The producer price index for all commodities, PPI (not seasonally adjusted; base year 1982=100), CPI for meat poultry and fish, CPIMPF (U.S. city average; not seasonally adjusted; base year 1982-1984=100), and CPI for all commodities, CPIALL (U.S. city average; not seasonally adjusted; base year 1982-1984=100), were obtained for each month from the U.S. Department of Labor's Bureau of Labor Statistics (BLS) website. All index values were then converted to base year $=2007$. The CPIMPF was further divided by the CPIALL for each month in order for the variable to reflect how consumer prices of meat, poultry, and fish were changing relative to overall inflation. Monthly data on total pounds and total current values of brown shrimp landings for the entire U.S. were obtained from the National Marine Fisheries Service (http://www.st.nmfs.noaa.gov/st1/).

\section{Results}

\section{The HSC Model of Production}

HSC estimate three different model types with a number of robustness checks. The results differ some across models, but they are qualitatively the same and quantitatively similar. In order to estimate an individual-level model and recover the missing parameters from our stock model, we use the hypoxia coefficient from the HSC differenced model as the true effect and estimate the 
production function in equation 2 with equation 3 as the dependent variable. The latter is essential for estimating fishing behavior in the next section, as stock is a key determinant of fishing participation.

The results of the production model are shown in table 1. All coefficients are highly significant with their expected signs. Note that October is the base month, so the Month 10 dummy variable is dropped. Not surprisingly, higher initial abundance increases catch; larger vessels catch more; and cumulative past harvest (fishing mortality from earlier in the season) decreases catch.

\section{Vessel Participation}

The results of the binary logit model conform to our theoretical expectations (table 2). All results are significant at the $1 \%$ level. Most importantly for our welfare analysis, shrimp vessels are more likely to fish on days with higher prices. The fact that fishing responds positively to price indicates that the supply curve is upward sloping, and our particular result suggests that the curve is not perfectly inelastic. This result, in turn, means that revenue losses from hypoxia are an overstatement of producer losses. Vessels also fish more often when the stock is larger, which is consistent with other research on fishing participation that embeds a stock model into the stock covariate (Smith, Zhang, and Coleman 2008). In the North Carolina shrimp case, responsiveness to stock implies that the fleet at least indirectly responds to the presence of hypoxia.

Vessels fish less often when weather conditions are unfavorable (big waves or high winds). They also fish less intensively on weekends. While it is difficult to separate out market and institutional effects on weekend participation from cultural ones (Smith and Wilen 2005), there is an obvious institutional driver of this tendency in the North Carolina brown shrimp fishery. Inland waterways in North Carolina-including the Pamlico Sound, which is the state's largest 
shrimping ground - are closed to shrimp trawling on weekends to protect the recreational fishing and boating sectors. On weekends shrimp vessels must incur the additional costs of steaming to the open ocean, and fleet participation is significantly lower. Higher diesel prices also decrease the probability of fishing. This result is not surprising in light of the fuel intensiveness of bottom trawling.

We control for the effects of vessel length on participation as a means to capture observable heterogeneity in the fleet. The positive effect of the linear term and negative effect of the quadratic term indicate that larger vessels (up to 73 feet) are more likely to participate. The majority of the vessels in the North Carolina fleet are below this cutoff. Small vessels are less likely to participate possibly because they can more easily re-gear to participate in other fisheries. Beyond the cutoff, less participation of the very large vessels could indicate switching out of the fishery to other regions. Our data set does not allow us to test this hypothesis. We note that this problem is typical with fishing microdata in which the boundaries of the data set are limited to a particular fishery.

The year fixed effects are significant and likely reflect a combination of factors. To the extent that our stock model imperfectly captures inter-annual variation, year fixed effects pick up recruitment class strength. They also could capture favorable or unfavorable circumstances in substitute fisheries within the Mid-Atlantic region or for other shrimp fisheries elsewhere in the U.S. While it may be difficult to re-gear a shrimp trawler or to move to another region (e.g., Gulf of Mexico) on a daily time step, many of these vessels can easily be outfitted for other fisheries inter-annually or can readily steam to another fishing region in the off-season.

\section{The Demand Side}


We run demand models in price-dependent form to explore the extent to which demand is inelastic. We find no evidence that price is endogenous in the NC shrimp market, and in the welfare analysis we treat demand as perfectly elastic. This result likely reflects the small market size of NC relative to the global market for shrimp and a high level of market integration. Landings in NC are just too small to influence prices, although our small number of observations serves as a caveat. Initially, we came to this conclusion by running a number of individual specifications. Inverse demand results were generally consistent with economic theory (Nichols 2008). However, most of the results were not significant. Only the two substitute product covariates for price of imported shrimp and price of other U.S. shrimp (shrimp from regions outside North Carolina) were consistently significant with the expected sign. Income and the price index for meat, fish, and poultry had their expected signs but were not significant. Most importantly, the coefficient on shrimp quantity landed was either not significant or had a positive sign rather than a negative one.

Given the weak performance of the demand models and the coarse temporal resolution of the data, we explore the potential for a negative coefficient on quantity landed by running a complete universe of possible model specifications. To this end, we include income; price of other U.S. shrimp landings; price of shrimp imports; relative CPI of meat, fish, and poultry; month; and month squared as candidate exogenous variables (six total variables in addition to quantity landed and a constant) in the demand specification. Time trends (month and month squared) could be supply shifters that proxy for nonlinear von Bertalannfy growth over the course of the year, but they also may reflect seasonal demand. As such, they are included as exogenous variables but cannot be excluded from demand. Candidate instruments include number of 
hypoxic days in the previous two months, diesel prices, and number of days in the month in which daily maximum wave height exceeded five feet.

We first run all possible specifications using ordinary least squares and all usable observations ( $\mathrm{n}=61)$. We include a constant and the quantity landed in every specification. That leaves $2^{6}=64$ total model specifications. In the 64 sets of results, the coefficient on quantity landed is always positive and is significant in 38 specifications. As such, the OLS models provide no evidence of a downward sloping demand for $\mathrm{NC}$ shrimp. We run instrumental variables for each of these 64 specifications using one instrument at a time. There are three possible instruments for a total of 192 models. Only 47 out of 192 models have a negative coefficient on quantity landed, and none of these coefficients are significant. Of the remaining models, there are 60 with positive and significant coefficients on quantity landed. Taken together, these models provide no evidence for downward sloping demand for NC shrimp.

\section{Welfare Effects}

We compute welfare effects on a daily basis. Figure 1 shows examples of six different days in 2004 in which the hypoxia effect, other supply conditions, and prices vary. Because the demand curve is statistically indistinguishable from being perfectly elastic, the welfare effect is comprised of producer surplus loss. In the figure, producer surplus change in each panel is the area between the supply curves and under the demand curve (shaded). For the case of zero hypoxia, the supply schedule approximately rotates clockwise about the origin relative to the business as usual (BAU) case. The shaded area is the daily welfare loss from hypoxia (or gain from eliminating hypoxia). Note that surplus losses vary substantially across days and are highest during the summer months (July, August, September) when hypoxia is typically most severe. 
This variation reflects not only seasonal variation in the severity of hypoxia but also fluctuating shrimp prices, abundance, fuel prices, and other conditions that affect supply.

We compute annual totals for losses from hypoxia in table 3. HSC find that revenue losses from hypoxia for the $\mathrm{NC}$ brown shrimp fishery are in the range of $\$ 1.25$ million per year. In light of this finding, the average welfare effect of $\$ 261,372$ per year in our analysis that allows behavioral adjustment is surprisingly small (less than $25 \%$ of the revenue losses computed in HSC). Behavioral adjustment along the intensive margin is clearly an important adaptation strategy for the shrimp fleet in response to hypoxia.

Looking at each year rather than just the average across years, we see that losses are correlated with the number of hypoxic days. This finding is not surprising. However, the correlation is not strong, and the relationship appears to be nonlinear. Moreover, the real price per pound of shrimp is negatively correlated with welfare losses from hypoxia, though only weakly. This result is curious at first blush. Higher prices tend to draw more effort into the fishery, and when hypoxia reduces available stocks given this higher level of effort, losses should be greater. However, conditional on a particular hypoxia effect, higher prices lead to more responsiveness of the fleet to the hypoxia (figure 1). This effect acts in the other direction. Understanding this phenomenon and whether it is robust requires further research. One possibility is that this effect reflects unobserved heterogeneity. Perhaps high prices and high abundances are necessary to draw latent effort into the fishery. If prices are high, the effect of reduced abundance from hypoxia on effort will be more pronounced due to the presence of a more responsive part of the fleet. More adjustment on the intensive margin further attenuates the losses from hypoxia.

\section{Discussion}


Hypoxia can affect shrimp stocks and the associated harvests by increasing mortality, reducing growth and/or reproduction, and increasing catchability of shrimp by concentrating them on the edges of hypoxic areas. HSC combine trip-level fishing micro-data with continuous-time water quality monitoring data to quantify the effects of hypoxia on shrimp catches. Using these finely resolved data, they are able to account for both instantaneous and lagged effects of low oxygen that could not be explored with aggregate-level data. HSC compute revenue losses by weighting time-dependent catch losses by the corresponding shrimp prices. These revenue losses are welfare effects under the assumptions that supply of North Carolina brown shrimp is perfectly inelastic (vertical) and demand for North Carolina brown shrimp is perfectly elastic (horizontal). In this article, we find support for the latter assumption but not for the former. In the logit model, we find that supply is responsive to economic factors as expected, including price. As a result of fleet behavioral responses coupled with perfect elasticity in the demand model, we estimate that the economic benefits to the fishery of reduced hypoxia are less than a quarter of those estimated from a model that assumes no behavioral adjustment in the fishery.

Several caveats of our analysis are in order. On the consumer side, we fail to reject the hypothesis that price is unresponsive to quantity produced in North Carolina. This outcome is believable given the small fraction of the total market the North Carolina brown shrimp fishery represents. However, it could also be the case that the demand is close to flat but with such limited degrees of freedom, the econometric model cannot resolve this slope. Assuming that consumer surplus changes are zero based on the econometrics is extremely conservative, and the true welfare consequences of hypoxia for the shrimp market may be larger.

Although our model is designed to isolate the net effect of hypoxia on the shrimp fishery, the full ecological consequences of hypoxia and related environmental disturbances are unknown. It 
may be that predators or prey of shrimp are more affected by hypoxia than shrimp themselves. If predators are more affected, the net effect that we calculate is likely smaller than the gross effect of hypoxia on shrimp, and some of the difference is due to reduced predation. If effects on shrimp prey are larger, then the opposite would be true.

We also assume no further entry into the shrimp fishery. Smith (2007) allows for dynamic entry and exit in studying the impacts of hypoxia on the North Carolina blue crab fishery, but in that case there was no intra-seasonal effort model. The assumption of no further entry may not be unreasonable in the case of shrimp. There appears to be significant latent capacity amongst vessels that only occasionally participate but that are still a part of our dataset. If conditions in the fishery improve, these vessels likely would participate more within each season, and our model captures this effect. But if additional vessels would enter the fishery across seasons, we do not capture this feature and potentially overstate the welfare consequences of hypoxia.

While there is some concern about overstating welfare losses from not modeling entry and exit, our model of supply could be understating the losses. We focus our analysis on the main fishing ground of Pamlico Sound, which is adjacent to the Neuse River Estuary for which we have detailed water quality data. Our participation model analyzes whether vessels fish in the Pamlico Sound or not. Vessels that switch to other locations due to reduced abundance (potentially due to hypoxia) could be losing more from hypoxia than they would by assuming that they are not fishing. For example, consider a vessel that deliberately fishes in the open ocean rather than Pamlico Sound due to the effects of hypoxia on shrimp stocks in the Sound. Suppose that revenues from the same amount of effort are $10 \%$ lower in the open ocean than they would have been had the vessel fished in Pamlico Sound and the Pamlico had been pristine. The losses in this case would be the $10 \%$ difference in revenue. Our model discounts this $10 \%$ as if the 
vessel does not choose to fish at all and saves all of its costs. This effectively flattens the supply curve. In future work, we plan to explore alternative ways of estimating the participation model and the robustness of our findings of small welfare effects.

On a broader level, our analysis raises questions about how best to evaluate the overall costs and benefits of reducing hypoxia. First, what is the relevant management context in which to evaluate the benefits of reduced nutrient pollution? Our empirical results are contingent on the particular management regime in place for the shrimp fishery, namely open access. By empirically modeling behavioral responses, we are essentially isolating the effects of one externality (hypoxia due to nutrient pollution) while holding another externality (a common-pool resource failure) constant. Theoretically, the value of improved water quality will be greatest when the natural resource is managed optimally (McConnell and Strand 1989). In our particular case, ongoing research on the shrimp fishery in North Carolina suggests that the benefits of rationalization would be far greater than the benefits of reducing hypoxia and maintaining open access (Huang and Smith 2010). This finding is consistent with conclusions in Smith (2007) that rationalizing the North Carolina blue crab fishery would generate economic gains as much as an order of magnitude larger than those from reducing hypoxia. The question is not to rationalize or to reduce pollution. Rather, for purposes of doing benefit-cost analysis, should the benefits of improved water quality be those contingent on maintaining a common-pool resource failure or those that would materialize hypothetically from cleaning up the pollution and solving the commons simultaneously?

A second and more challenging question is how to approach the benefits of reduced nutrient pollution that are highly diffuse. The costs of reducing nutrient loading in the Neuse River are expected to be substantial, owing to the fact that nutrient pollution is a complex non-point source 
problem (Schwabe 2001). Weighing benefits from just one fishery against these costs will not pass a benefit-cost test, but such an exercise would be an unreasonable approach to benefit-cost analysis. Improving water quality has many benefits that span not just the state's two largest fisheries (blue crab and shrimp) but many other commercial and recreational fisheries, recreational boating and swimming, and overall ecosystem health. The challenge is that these benefits are highly diffuse and, therefore, difficult to quantify. Just computing fishery benefits alone would involve running numerous parallel studies to the one we describe herein. An important question for future research is to evaluate the potential use of benefits transfer to quantify benefits of hypoxia reduction across different systems and sub-systems.

Our empirical work is part of a growing literature that examines the economic dimensions of fishery-ecosystem interactions. Beyond nutrient pollution, empirical work is beginning to examine multispecies issues (Sanchirico, Smith, and Lipton 2008), the impacts of habitat loss on fisheries (Barbier and Strand 1998), invasive species (Knowler and Barbier 2005), spatial aspects of marine ecosystems (Smith, Sanchirico, and Wilen 2009), and tradeoffs between fishing and marine mammal conservation (Hicks and Schnier 2008; Haynie and Layton 2009). By studying fishery-ecosystem interactions, we hope to infuse the growing enthusiasm for marine ecosystembased management with sound economic analysis grounded in empirical data. 


\section{References}

Barbier, E.B., and I. Strand. 1998. Valuing Mangrove-Fishery Linkages: A Case Study of Campeche, Mexico. Environmental and Resource Economics 12:151-56.

Borsuk, M.E., C.A. Stow, R.A. Luettich, Jr., H.W. Paerl, and J.L. Pinckney 2001. Modelling Oxygen dynamics in an Intermittently Stratified Estuary: Estimation of Process Rates Using Field Data. Estuarine, Coastal, and Shelf Science 52:33-49.

Breitburg, D.L., D.W. Hondorp, L.A. Davias, and R.J. Diaz. 2009. Hypoxia, Nitrogen, and Fisheries: Integrating Effects Across Local and Global Landscapes. Annual Review of Marine Science 1:329-49.

Buzzelli, C.P., R.A. Luettich, Jr., S.P. Powers, C.H. Peterson, J.E. McNinch, J.L. Pinckney, and H.W. Paerl. 2002. Estimating the Spatial Extent of Bottom-water Hypoxia and Habitat Degradation in a Shallow Estuary. Marine Ecology Progress Series 230:103-12.

Clark, C.W. 1990. Mathematical Bioeconomics: The Optimal Management of Renewable Resources. New York: Wiley.

Craig, J.K. 2012. Aggregation on the Edge: Effects of Hypoxia Avoidance on the Spatial Distribution of Brown Shrimp and Demersal Fishes in the Northern Gulf of Mexico. Marine Ecology Progress Series 445:75-95.

Craig, J.K., and L.B. Crowder. 2005. Hypoxia-induced Habitat Shifts and Energetic Consequences in Atlantic croaker and Brown Shrimp on the Gulf of Mexico shelf. Marine Ecology Progress Series 294:79-94.

Craig, J.K., C.D. Gray, C.M. McDaniel, T.L. Henwood, and J.G. Hanifen. 2001. Ecological effects of hypoxia on fish, sea turtles, and marine mammals in the northwestern Gulf of Mexico. Coastal Hypoxia: Consequences for Living Resources and Ecosystems. Coastal 
and Estuarine Studies 58, N.N. Rabalais and R.E. Turner, eds., pp. 269-291. Washington, D.C.: American Geophysical Union.

Diaz, R.J, and R. Rosenberg. 2008. Spreading Dead Zones and Consequences for Marine Ecosystems. Science 321:926-29.

Diaz, R.J., and A. Solow. 1999. Ecological and Economic Consequences of Hypoxia. Topic 2. Gulf of Mexico Hypoxia Assessment. NOAA Coastal Ocean Program Decision Analysis Series. NOAA COP, Silver Springs, MD.

Eby, L.A., and L.B. Crowder. 2002. Hypoxia-based Habitat Compression in the Neuse River Estuary: Context-dependent Shifts in Behavioral Avoidance Thresholds. Canadian Journal of Fisheries and Aquatic Sciences 59:952-65.

Eby, L.A., L.B. Crowder, C.M. McClellan, C.H. Peterson, and M.J. Powers. 2005. Habitat Degradation from Intermittent Hypoxia: Impacts on Demersal Fishes. Marine Ecology Progress Series 291:249-62.

Fontaine, C.T., and R.A. Neal. 1971. Length-weight Relations for Three Commercially Important Penaeid Shrimp in the Gulf of Mexico. Transactions of the American Fisheries Society 100:584-86.

Gleason, D.F., and G.M. Wellington. 1988. Food Resources of Postlarval Brown Shrimp (Penaeus aztecus) in a Texas Salt Marsh. Marine Biology 97:329-37.

Hagy, J. D., W. R. Boynton, C.W. Keefe, and C.V. Wood. 2004. Hypoxia in Chesapeake Bay, 1950-2001: Long-term Change in Relation to Nutrient Loading and River Flow. Estuaries 27:634-58.

Haynie, A.C., and D.F. Layton. 2010. An Expected Profit Model for Monetizing Fishing Location Choices. Journal of Environmental Economics and Management 59:165-76. 
Hicks, R. L., and K. E. Schnier. 2008. Eco-labeling and Dolphin Avoidance: A Dynamic Model of Tuna Fishing in the Eastern Tropical Pacific. Journal of Environmental Economics and Management 56:103-16.

Holthuis, L. B. 1980. FAO Species Catalogue Vol.1 - Shrimps and Prawns of the World. An Annotated Catalogue of Species of Interest to Fisheries. Rome: Food and Agriculture Organization of the United Nations.

Huang, L., and M.D. Smith. 2010. The Dynamic Efficiency Costs of Common-Pool Resource Exploitation. In Review.

Huang, L., M.D. Smith, and J.K. Craig. 2010. Quantifying the Economic Effects of Hypoxia on a Fishery for Brown Shrimp Farfantepenaeus aztecus. Marine and Coastal Fisheries: Dynamics, Management, and Ecosystem Science 2:232-48.

Keithly, W. R., Jr., and P. Poudel. 2008. The Southeast U.S. Shrimp Industry: Issues Related to Trade and Antidumping Duties. Marine Resource Economics 23:459-83.

Knowler, D., and E. Barbier. 2005. Managing the Black Sea Anchovy Fishery with Nutrient Enrichment and a Biological Invader. Marine Resource Economics 20:263-85.

Lenihan, H.S., C.H. Peterson, J.E. Byers, J.H. Grabowski, G.W. Thayer, and D.R. Colby 2001. Cascading of Habitat Degradation: Oyster Reefs Invaded by Refugee Fishes Escaping Stress. Ecological Applications 11:764-82.

Lipton, D. W., and R. Hicks. 2003. The Cost of Stress: Low Dissolved Oxygen and Recreational Striped Bass (Morone saxatilis) Fishing in the Patuxent River. Estuaries 26:310-15.

Massey, D.M., S.C. Newbold, and B. Gentner. 2006. Valuing Water Quality Changes Using a Bioeconomic Model of a Coastal Recreational Fishery. Journal of Environmental Economics and Management 52:482-500. 
McConnell, K.E., and I.E. Strand. 1989. Benefits from Commercial Fisheries when Demand and Supply Depend on Water Quality. Journal of Environmental Economics and Management 17:284-92.

McCoy, E.G. 1968. Migration, Growth and Mortality of North Carolina Pink and Brown Penaeid Shrimps. North Carolina Department of Conservation and Development, Division of Commercial Sports Fisheries, Special Science Report 15.

Miller, D.C., S.L. Poucher, and L. Coiro. 2002. Determination of Lethal Dissolved Oxygen Levels for Selected Marine and Estuarine Fishes, Crustaceans, and a Bivalve. Marine Biology 140:287-96.

Minello, T. J., R.J. Zimmerman, and E.X. Martinez. 1989. Mortality of Young Brown Shrimp Penaeus aztecus in Estuarine Nurseries. Transactions of the American Fisheries Society 118:693-708.

Mistiaen, J.A., I.E. Strand, and D. Lipton. Effects of Environmental Stress on Blue Crab (Callinectes sapidus) Harvests in Chesapeake Bay Tributaries. Estuaries 26(2A):316-22.

Moullac, G. L., C. Soyez, D. Salnier, D. Ansquer, and J. Avarre. 1998. Effect of Hypoxic Stress on the Immune Response and the Resistance to Vibriosis of the Shrimp Penaeus stylirostris. Fish \& Shellfish Immunology 8: 621-29.

National Marine Fisheries Service (NMFS). 2008.

<http://www.nmfs.noaa.gov/fishwatch/species/brown_shrimp.htm>. Retrieved February 24.

National Research Council (NRC). 2000. Clean Coastal Waters: Understanding and Reducing the Effects of Nutrient Pollution. Washington, D.C.: National Academy Press. 
Nichols, L.A.B. 2008. The Welfare Effects of Hypoxia in the North Carolina Brown Shrimp Fishery. Unpublished Masters Project. Duke University.

North Carolina Division of Marine Fisheries (NCDMF). 2006. North Carolina Fishery Management Plan: Shrimp. North Carolina Division of Marine Fisheries.

—. 2007. Shrimp. <http://www.ncfisheries.net/shellfish/shrimp1.htm〉. Retrieved March 2, 2008.

Paerl, H.W., J.L. Pinckney, J.M. Fear, B.L. Peierls. 1998. Ecosystem Responses to Internal Watershed Organic Matter Loading: Consequences for Hypoxia and Fish Kills in the Eutrophying Neuse River Estuary, North Carolina, USA. Marine Ecology Progress Series 166:17-25.

Rabalais, N. N., W.J. Wiseman, Jr., R. E. Turner, D. Justic, and B.K. Sen Gupta (1996). Nutrient Changes in the Mississippi River and System Responses on the Adjacent Continental Shelf. Estuaries 19(2B):386-407.

Reynolds-Fleming, J.V., and R.A. Luettich. 2004. Wind-driven Lateral Variability in a Partially Mixed Estuary. Estuarine, Coastal and Shelf Science 60:395-407.

Rosas, C., E. Martinez, G. Gaxiola, R. Brito, E. Diaz-Iglesia, and L.A. Soto. 1998. Effect of Dissolved Oxygen on the Energy Balance and Survival of Penaeus setiferus Juveniles. Marine Ecology Progress Series 174:67-75.

Sanchirico, J.N., M.D. Smith, and D.W. Lipton. 2008. An Empirical Approach to Ecosystembased Fishery Management. Ecological Economics 64:586-96.

Schwabe, K.A. 2001. Nonpoint Source Pollution, Uniform Control Strategies, and the Neuse River Basin. Review of Agricultural Economics 23:352-69. 
Sheridan, P.F., D.L. Trimm, and B.M. Baker. 1984. Reproduction and Food Habits of Seven Species of Northern Gulf of Mexico Fishes. Contributions in Marine Science 27:175-204.

Smith, M.D. 2007. Generating Value in Habitat-dependent Fisheries: The Importance of Fishery Management Institutions. Land Economics 83:59-73.

Smith, M.D., J.N. Sanchirico, and J.E. Wilen. 2009. The Economics of Spatial-dynamic Processes: Applications to Renewable Resources. Journal of Environmental Economics and Management 57: 104-21.

Smith, M.D., and J.E. Wilen. 2005. Heterogeneous and Correlated Risk Preferences and Behavior of Commercial Fishermen: The Perfect Storm Dilemma. The Journal of Risk and Uncertainty 31:53-71.

Smith, M.D., J. Zhang, and F.C. Coleman. 2006. Effectiveness of Marine Reserves for LargeScale Fisheries Management. Canadian Journal of Fisheries and Aquatic Sciences 63:153-64.

—. 2008. Econometric Modeling of Fisheries with Complex Life Histories: Avoiding Biological Management Failures. Journal of Environmental Economics and Management 55:265-80.

Stierhoff, K.L., T.E. Targett, and J.H. Power. 2009. Hypoxia-induced Growth Limitation of Juvenile Fishes in an Estuarine Nursery: Assessment of Small-scale Temporal Dynamics using RNA:DNA. Canadian Journal of Fisheries and Aquatic Sciences 66:1033-47.

Stow, C.A., C. Roessler, M.E. Borsuk, J.D. Bown, and K.H. Reckhow. 2003. Comparison of Estuarine Water Quality Models for Total Maximum Daily Load Development in the Neuse River Estuary. Journal of Water Resources Planning and Management 129:30714. 
Thomas, P., S. Rahman, I.A. Khan, and J.A. Kummer. 2007. Widespread Endocrine Disruption and Reproductive Impairment in an Estuarine Fish Population Exposed to Seasonal Hypoxia. Proceedings of the Royal Society B 274(1626): 2693-702.

Wannamaker, C.M., and J.A. Rice. 2000. Effects of Hypoxia on Movements and Behavior of Selected Estuarine Organisms from the Southeastern United States. Journal of Experimental Marine Biology and Ecology 249: 145-63.

Wu, R.S.S. 2002. Hypoxia: From Molecular Responses to Ecosystem Responses. Marine Pollution Bulletin 45:35-45.

Zhang, J., and M.D. Smith. 2011. Estimation of a Generalized Fishery Model: A Two-Stage Approach. The Review of Economics and Statistics 93: 690-99.

Zimmerman, R., Nance, J., and J. Wiams. 1996. Trends in Shrimp Catch in the Hypoxic Area of the Northern Gulf of Mexico. Galveston Laboratory, National Marine Fisheries Service. Proceedings of the First Gulf of Mexico Hypoxia Management Conference. EPA-55-R97-001. Washington, D.C. 
Figure 1. Examples of Empirical Surplus Changes from Hypoxia
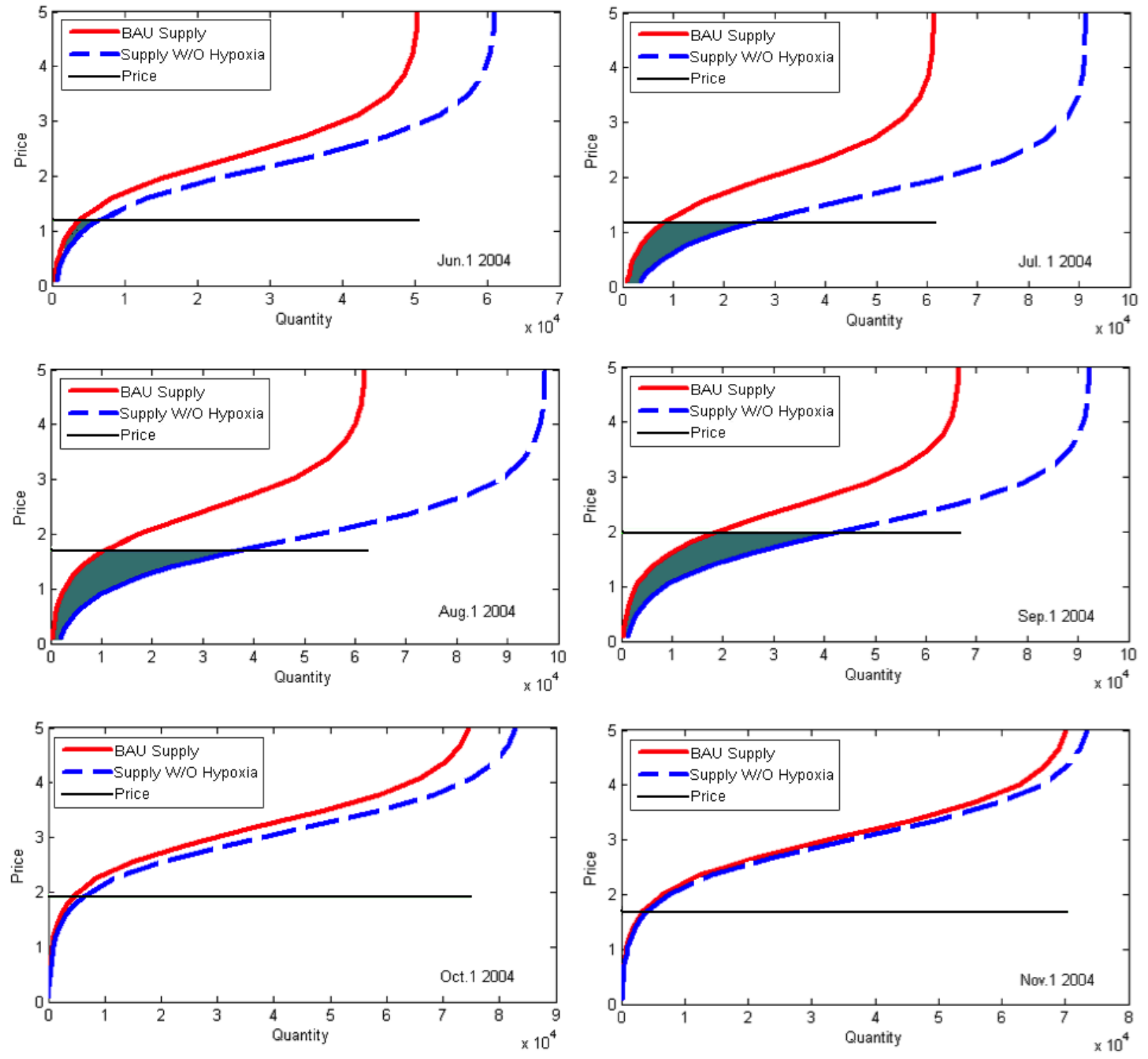


\section{Table 1}

\section{Production Model Results}

$\begin{array}{lrrr} & \begin{array}{r}\text { Parameter } \\ \text { Estimate }\end{array} & \begin{array}{r}\text { Standard } \\ \text { Error }\end{array} & \text { P-Value } \\ \text { Intercept } & 3.11072 & 0.26234 & <.0001 \\ \text { Month5 } & 0.33287 & 0.08267 & <.0001 \\ \text { Month6 } & 0.69113 & 0.02998 & <.0001 \\ \text { Month7 } & 0.94804 & 0.02139 & <.0001 \\ \text { Month8 } & 0.37381 & 0.02054 & <.0001 \\ \text { Month9 } & 0.20682 & 0.02176 & <.0001 \\ \text { Month11 } & -0.58513 & 0.04741 & <.0001 \\ \text { Initial shrimp abundance } & 0.13433 & 0.01507 & <.0001 \\ \text { Log(vessel length) } & 1.73395 & 0.01543 & <.0001 \\ \text { Accumulated harvest } & -0.00000841 & 5.50 \mathrm{E}-07 & <.0001\end{array}$

Note: The dependent variable is given by equation 3 . 
Table 2

Logit Participation Model Results

$\begin{array}{rrrr} & & \text { Standard } & \\ \text { Parameter } & \text { Estimate } & \text { Error } & \text { P-value } \\ \text { Year1999 } & -1.5322 & 0.2008 & <.0001 \\ \text { Year2000 } & 1.9579 & 0.2184 & <.0001 \\ \text { Year2001 } & 1.489 & 0.1983 & <.0001 \\ \text { Year2002 } & 2.0209 & 0.1905 & <.0001 \\ \text { Year2003 } & 2.3311 & 0.2011 & <.0001 \\ \text { Year2004 } & 2.8797 & 0.2267 & <.0001 \\ \text { Year2005 } & 5.5184 & 0.2787 & <.0001 \\ \text { Price } & 2.0362 & 0.0329 & <.0001 \\ \text { Stock } & 0.5485 & 0.0992 & <.0001 \\ \text { Wind Speed } & -0.0263 & 0.00511 & <.0001 \\ \text { Wave Height } & -0.484 & 0.0222 & <.0001 \\ \text { Weekend } & -0.9603 & 0.0239 & <.0001 \\ \text { Diesel Price } & -0.0623 & 0.00145 & <.0001 \\ \text { Length } & 0.0351 & 0.00439 & <.0001 \\ \text { Length * Length } & -0.00024 & 0.000037 & <.0001\end{array}$

Note: The dependent variable is whether to go fishing on the day. 
Table 3

Summary of the Welfare Effects of Hypoxia

$\begin{array}{rrrr} & \begin{array}{r}\text { Number } \\ \text { Hypoxic }\end{array} & \begin{array}{r}\text { Weighted } \\ \text { Avg. Price }\end{array} & \begin{array}{r}\text { Welfare } \\ \text { Loss } \\ (2005 \$ / \text { lb. })\end{array} \\ \text { Year } & \text { Days } & 3.22 & 23005 \$) \\ 1999 & 50 & 2.94 & 254,008 \\ 2000 & 38 & 2.82 & 457,274 \\ 2001 & 80 & 2.04 & 191,448 \\ 2002 & 43 & 2.17 & 326,214 \\ 2003 & 69 & 2.28 & 454,141 \\ 2004 & 87 & 2.07 & 123,081 \\ 2005 & 57 & 2.51 & 261,372 \\ \text { Mean } & 61 & & \end{array}$


Appendix A - Derivation of the Catch Equation

Let $C$ represent the average shrimp landings per trip (lbs./trip) made on a particular day $t$ of a year $y . C$ is a nonlinear function of fishing effort, which we measure as the average number of trips $\left(K_{y t}\right)$ and the average length of vessels that make those trips on each day of the year (Len). Other terms in the model are month- and gear-specific catchability $\left(q_{y m, g}\right.$, in which $m$ indicates month and $g$ indicates gear type), and shrimp biomass $\left(X_{y t}\right)$. Catchability is a bio-mechanical coefficient that converts biomass and fishing effort into catch, and $\varepsilon$ is an error term assumed to be independently and identically distributed (i.i.d.) with a normal distribution:

$$
C_{y t}=q_{y m, g} K_{y t}^{\alpha} \operatorname{Len}_{y t}^{\beta} X_{y t} e^{\varepsilon_{y t}}
$$

This form of the production function allows $\alpha$ and $\beta$ to measure curvature in the relationship between catch and effort (see Smith, Zhang, and Coleman 2006). Shrimp biomass $\left(X_{y t}\right)$ can be decomposed into the total number of shrimp $\left(Z_{y t}\right)$ and individual shrimp weight $\left(w_{t}\right)$ :

$$
X_{y t}=z_{y t} w_{t}
$$

$w_{t}$ reflects the baseline intra-annual growth before accounting for environmental factors, so it is only a function of $t$ and not specific to a particular year $y$. We use the standard von Bertalanffy growth function to model shrimp growth in length and an allometric function to relate length and weight. The von Bertalanffy function is:

$$
\boldsymbol{L}(\boldsymbol{t})=\boldsymbol{L} \infty\left(1-e^{\delta t}\right)
$$

where $L$ denotes the total length of shrimp and $\boldsymbol{L} \infty$ is the terminal length. The parameter $\delta$ captures the "decay" rate, or the rate at which shrimp approach asymptotic size. Shrimp weight is represented as an allometric function of shrimp length:

$$
w_{t}=\omega L(t)^{\eta}
$$


The total baseline number of shrimp $\left(Z_{y t}\right)$ in equation A2 is year-specific to account for recruitment variability and declines over the season due to natural mortality, emigration, and fishing mortality:

$$
z_{y t}=z_{y(t-1)} * e^{-\Delta m_{0 t}-\Delta m_{1 t}} * e^{m_{f} \frac{H_{y(t-1)}}{w_{t-1}}}
$$

In the above equation, $\Delta m_{0 t}, \Delta m_{1 t}$, and $\mathrm{m}_{\mathrm{f}}$ are the loss rates of shrimp per day due to natural mortality, emigration from the system, and fishing mortality, respectively. The first two factors, $\Delta m_{0 t}$ and $\Delta m_{1 t}$, are also not year-specific. To simplify the model, the fishing mortality parameter, $m_{f}$, is set constant over time. $H_{y(t-1)}$ is the total catch (in lbs.) on the previous day for the entire fleet, and $\frac{H_{y(t-1)}}{w_{t-1}}$ converts pounds to the number of shrimp landed. Equations A1-A5 describe the basic relationships among shrimp harvest, fishing effort, and stock dynamics. Substituting Equation A1 with Equations A2 (biomass) and A5 (abundance) gives the following:

$$
C_{y t}=q_{y m, g} K_{y t}^{\alpha} \operatorname{Len}_{y t}^{\beta} z_{y(t-1)} * e^{-\Delta m_{0 t}-\Delta m_{1 t}} * e^{m_{f} \frac{H_{y(t-1)}}{w_{t-1}}} * w_{t} e^{\varepsilon_{y t}}
$$

In addition to the intrinsic growth variables above, external environmental factors, including dissolved oxygen, temperature, and salinity may affect shrimp harvest. The following equation captures the influence of various environmental factors:

$$
C_{y t}=q_{y m, g} K_{y t}^{\alpha} \operatorname{Len}_{y t}^{\beta} z_{y(t-1)} * e^{-\Delta m_{0 t}-\Delta m_{1 t}} * e^{m_{f} \frac{H_{y(t-1)}}{w_{t-1}}} * w_{t} * e^{a_{1} O I_{y t}+a_{2} T I_{y t}+a_{3} S I_{y t}} e^{\varepsilon_{y t}}
$$

In this equation, $O I, T I$, and $S I$ are binary indices of whether particular environmental factors (dissolved oxygen, temperature, and salinity, respectively) are within a tolerable range based on information in the literature, al-a3 are parameters, and other terms are as defined previously. See HSC for details on environmental thresholds. Note that the effects of environmental factors 
captured by equation A7 could be due to multiple, interdependent mechanisms that influence shrimp growth, mortality, migration, or catchability to the fishery. Our model does not distinguish the particular mechanism(s) by which environmental factors influence shrimp harvest.

In equation A7, al-a3 measure the marginal daily effects of the environmental factors on shrimp catch (log-transformed). Ultimately, we are interested in the cumulative effects of each environmental factor over time and the direction and magnitude of their effect on harvest. If we accumulate the effects over time, equation $\mathrm{A} 7$ becomes:

$$
C_{y t}=q_{y m, g} K_{y t}^{\alpha} \operatorname{Len}_{y t}^{\beta} z_{y 0} * e^{-m_{0 t}-m_{1 t}} * e^{m_{f} \sum_{i=0}^{t-1} \frac{H_{y i}}{w_{i}}} * w_{t} * e^{A} e^{\varepsilon_{y t}}
$$

in which:

$$
A=a_{1} \sum_{i=\tau-t+1}^{t} O I_{y i}+a_{2} \sum_{i=\tau-t+1}^{t} T I_{y i}+a_{3} \sum_{i=\tau-t+1}^{t} S I_{y i}
$$

where $Z_{y 0}$ is the initial number of shrimp in year y, and $\tau$ is the number of days over which the environmental effects are accumulated. For example, if $\tau=40$, the marginal effects of environmental conditions are aggregated over 40 days before harvest (i.e., 40-day lagged effect). This means that the occurrence of one day of hypoxia (dissolved oxygen is less than some threshold) has marginal effects on shrimp harvest that can extend over the following 40 days, after which there is no effect.

While the lagged effects of low dissolved oxygen on shrimp production might reasonably be assumed to operate in a threshold manner (where there is no effect until conditions are below some critical level), dissolved oxygen as well as other environmental factors may also have contemporaneous effects on shrimp harvest over the range of conditions experienced in the estuary. For example, we expect avoidance behavior to be a function of the severity of low 
oxygen and to appear on the same day. The effects on harvest could be negative or positive, depending on whether avoidance leads to aggregation along the edges of hypoxic areas (increases catchability) or disperses existing aggregations of shrimp (decreases catchability). Therefore, we developed the following equation to capture this broader range of potential environmental effects:

$$
C_{y t}=q_{y m, g} K_{y t}^{\alpha} \operatorname{Len}_{y t}^{\beta} z_{y 0} * e^{-m_{0 t}-m_{1 t}} * e^{m_{f} \sum_{i=0}^{t-1} \frac{H_{y i}}{w_{i}}} * w_{t} * e^{A} *\left(O_{y t}^{b_{1}} T_{y t}^{b_{2}} S_{y t}^{b_{3}}\right) e^{\varepsilon_{y t}}
$$

where $O_{t}$ is the dissolved oxygen concentration $\left(\mathrm{mg} \mathrm{l}^{-1}\right), T_{t}$ is the temperature $\left({ }^{\circ} \mathrm{C}\right)$, and $S_{t}$ is the salinity (ppt). Including both absolute values and binary indices to represent environmental effects in the model provides a flexible functional form that can capture the multiple levels over which environmental conditions may influence shrimp production and harvest.

In order to simplify the nonlinear estimation, we linearize equation A9 by taking the log of both sides:

$$
\begin{aligned}
& \ln C_{y t}=\ln q_{y m, g}+\alpha \ln K_{y t}+\beta \ln \text { Len }_{y t}+\ln z_{y 0}+\left(\ln w_{t}-m_{0 t}-m_{1 t}\right) \\
& m_{f} \sum_{i=0}^{t-1} \frac{H_{y i}}{w_{i}}+a_{1} \sum_{i=\tau-t+1}^{t} O I_{y i}+a_{2} \sum_{i=\tau-t+1}^{t} T I_{y i}+a_{3} \sum_{i=\tau-t+1}^{t} S I_{y i}+b_{1} \ln O_{y t} \\
& +b_{2} \ln T_{y t}+b_{3} \ln S_{y t}+\varepsilon_{y t} .
\end{aligned}
$$

This is the specification in equation 1. 